\title{
What We Expect from the European Action Plane for the Circular Economy?
}

\author{
Ferruccio Trifirò
}

Dipartimento Chimica Industriale “Toso Montanari” Viale Risorgimento N4 40136 Bologna, Italy

Corresponding Author Email: ferruccio.trifiro@ unibo.it

https://doi.org/10.18280/ti-ijes.642-421

Received: 12 April 2020

Accepted: 21 May 2020

\section{Keywords:}

circular economy, wastes, recycle, decarbosilation, digitalization

\begin{abstract}
This note has the objective to mention the European Commission Document on the Circular Economy presented on 11 March. The document has repeatedly stressed that creating a circular economy is the tool to achieve the decarbonisation of Europe by 2050. The activities on which it is necessary to invest and do research to increase the recycling and life of the products are: electronic and electrical equipments, batteries and vehicles, packaging, plastics, food, buildings and buildings. To facilitate the recycling and reuse of products it is necessary to eliminate the toxic substances in the products that are on the market and this is the sector in which chemistry is primarily involved.
\end{abstract}

\section{INTRODUCTION}

Europe has adopted the new Circular Economy Action Plan for a cleaner and more competitive Europe which was presented on 11 March 2020 in Brussels [1-6]. For the European Commission, the circular economy is the necessary choice to achieve environmental neutrality (ie primarily the ability to stop the production of greenhouse gases) by the European continent by 2050. Almost half of the total greenhouse gas emissions come from extraction and processing of resources. Currently the European economy has only $12 \%$ of secondary materials and resources obtained from wastes.

Immediate action must be taken on the entire life cycle of products starting from design, production, consumption, repair, reuse and recycling. Realizing the circular economy in Europe will also lead to an increase in employment. Currently many of the products and items on the market are designed as disposable, they are destroyed too quickly and therefore cannot be reused, repaired and recycled.

\section{CIRCULAR ECONOMY}

Between 1970 and 2017, the extraction and processing of materials such as biomass, fossil fuels, metals and minerals have tripled worldwide, an ever-growing trend that has caused greenhouse gas emissions, loss of biodiversity and water leaks. The circular economy project falls within the context of the larger Green Deal project [7] proposed by Ursula von der Leyen. The humanity, in thirty years, will increase wastes production by $70 \%$ and the global consumption of biomass, fossil fuels, metals and minerals will double within forty years. It is necessary to create a more sustainable and "green" economy in Europe against climate and environmental changes and against ruthless global competition on resources, using the circular economy together with the digital revolution. The plan of the circular economy project aims to increase confidence in recovered materials, which should normally become more efficient, safe and durable than the current ones. The various Reach directives on product safety must be followed and, in particular, the SVHC (Substances of Very High Concern) [8] substances that are highly worrying must be identified and techniques for removal from products and contaminants deriving from waste treatment must be developed. The Commission will act on several fronts: on the one hand, avoiding wastes production as much as possible and turning it into high quality secondary resources; on the other one, to act upstream, to prevent unsustainable products from entering the European market. The "upstream" action will then concern the design of the products, which must be designed to last longer, to be easier to reuse, to repair and to recycle; their production should incorporate the most of possible recycled material, instead of primary raw materials. The "downstream" action will instead concern consumers, who will have access to reliable information on the durability and repairability of products, introducing a true "right to repair". It is well known that some types of materials cannot be recycled, for example fossil fuels that are burned to produce energy or biomass that are consumed as food or fodder. The reduction of $\mathrm{CO}_{2}$ emissions must be $50 \%$ by 2030 and total by 2050 . The achievement of these objectives will radically transform Europe's production system bringing it to the forefront in terms of energy and environmental sustainability

\section{THE KEY PROUCTS OF THE ECONOMY}

The economic sectors, shown in this paragraph, are those considered the most important on which to act at the design and production level in order to create a circular economy. Taking action in these sectors will ensure that the resources currently used are kept for as long as possible within the EU, in order to minimize wastes, eliminate wastes and transform them into secondary resources.

The EU draft reads that by 2030 only the safest, most circular and sustainable products should be placed on the EU market. Furthermore, as highlighted in the text, the 
Commission will focus on defining the minimum sustainability requirements for products, so as to declare that those that do not comply with the previous requirements will be negligible on the European market.

The Electrical and Electronic Equipment are the products whose wastes increase the most, in an amount equal to $2 \%$ per year in Europe, and currently only less than $40 \%$ are recycled. It is necessary to increase the life of these products, making them more reusable and repairable by trying to improve the different components and software to increase their life. In addition, the "right to repair" must be implemented in this sector, that is to set up a return system at EU level to return or resell old telephones, mobile phones, tablets, cell phone chargers and similar devices (we will also consider developing a regime for their return at the end of the cycle). The Commission is planning to introduce the universal charger for mobile phones to help the environment by decreasing the number of items in circulation.

The idea of the EU Commission is also to make consumers more responsible by facilitating their access to reliable information on repairability and durability products to help them make sustainable choices from an environmental point of view.

For batteries and vehicles new legislations are needed for their reuse. In particular, a new regulatory framework will be created for batteries aimed at improving the quantity of batteries collected and recycled, guaranteeing the recovery of valuable materials and also fixing the level of recycled content in new batteries. New regulations on end-of-life vehicles are also needed to improve recycling efficiency, rules on the sustainable treat ment of waste oils will be proposed and a high percentage of recycling of electric cars will have to be guaranteed.

For packaging, whose average use in 2017 was $173 \mathrm{~kg}$ per European citizen, in 2030 it will be necessary to have a strategy to reuse or recycle them in a more economic way and to decrease the amount used. It is also necessary to verify the implementation of the past legislative initiative on the reuse of packaging in restaurant services.

Plastics demand will double in the next twenty years. It is necessary to use bioplastics or biodegradable or compostable plastics, eliminate the use of microplastics, implement measures for the recovery of plastics in water and reinforce the rules already introduced in the past on the elimination of disposable plastics. It is also necessary to increase the content of recycled plastic in the packaging, in construction materials and in vehicles sectors. In addition, it is important to implement stricter labelling in order to ensure that biodegradable plastics are more appreciated by consumers as they can produce environmental benefits. Furthermore, the directive on the ban on the use of plastic objects, such as plates, cutlery and disposable glasses, for the restaurant service should continue to be applied.

In the Food sector (food and water), in addition to what has been said above regarding packaging and dishes that must be reusable, a new legislative initiative is envisaged aimed at reducing food waste ( $20 \%$ of food is lost or goes to wastes in Europe). The reduction of food wastes in the EU will have to go "from the fields to the table". In addition, it will be necessary to make drinking water accessible in public places to reduce dependence on bottled water.

In the Textile sector, only $1 \%$ in the world is recycled into new textiles and $60 \%$ of the textiles used in Europe come from outside. We therefore need a strategy and new legislative initiatives for the reuse and recycling of textiles in Europe for 2025 and a separate location for textile wastes. Textiles are the fourth largest product by quantity of raw materials and water used and are the fifth in terms of greenhouse gas emissions.

The Construction and Building Maintenance sector uses $50 \%$ of non-recyclable materials, produces $35 \%$ of wastes and emits from 4 to $12 \%$ of greenhouse gases. The Commission will propose regulations for the introduction of recycled content requirements for some construction products and reduce the presence of carbon in construction products for greenhouse gas emissions.

\section{LESS WASTES MORE VALUES}

In Europe, 2.4 billion tons of wastes are produced each year, practically 5 tons per person. The amount of municipal wastes must be halved by 2030 and the strategies are as follows: increase separate wastes collection across Europe, limit disposable products and support the market for secondary raw materials.

To increase the circular economy, however, it is necessary to minimize the presence of toxic substances for mankind and the environment in the products to be recycled. It is necessary to increase knowledge of the toxicity of the substances present in products by implementing cooperation between the Academy and Industry. Remember the Stockholm Convention on POP (Persistent Organic Pollutants) substances to be eliminated from the market and no longer export toxic wastes [9].

The Commission therefore intends to reduce wastes by trying to eliminate wastes entirely or by transforming it into high quality secondary resources. It is also proposed to improve the classification and management of hazardous waste, also by aligning it with those envisaged for chemical products. In this scenario, chemistry can make a fundamental contribution because it is involved both in developing technologies that minimize the presence of dangerous substances in the articles on the market and in recycled materials and in quality control.

\section{CIRCULAR ECONOMY AND DIGITALIZATION}

Jobs in the circular economy increased by $4 \%$ between 2002 and 2008 and reached 4 million. Workers must have the necessary preparation to work in a circular economy. The link between digitalization and the circular economy must always be present, to create a production plant that, through design, reconstitutes and regenerates resources, that is, maintains production at a high level, minimizing waste and making sure that the resources used are kept as long as possible within the economy. Therefore circular and digital economy must be unified, avoiding a depletion of resources, decreasing pollution and increasing competitiveness and innovation. A European data space will be set up to improve the quality, importance and availability of product data; there is talk of an "electronic product passport" containing "mandatory digital information" relating to their characteristics. The Commission will examine measures to ensure that digital technologies and tools such as artificial intelligence, $5 \mathrm{G}$, the cloud, information processing at the edge of the network, where data is produced (edge computing) and the internet of things can accelerate and maximize the impact of interventions to tackle climate change 
and protect the environment. Digitization also offers new opportunities for remote monitoring of air and water pollution or for the monitoring and optimization of the use of energy and natural resources. Energy efficiency, recycling and reuse, greenhouse gas abatement must be these investments in industry in the coming years.

\section{CONCLUSIONS}

In conclusion, a circular economy has the objective of maintaining the value of products, materials and resources for as long as possible, returning to the market at the end of their use, minimizing the generation of waste. The areas of the circular economy are as follows: production and consumption, wastes management, secondary raw materials, competitiveness and innovation. The EU objective is to achieve climate neutrality by 2050 , indicating a series of measures relating to the entire life cycle of products by designing products with a greater use of recycled raw materials to last longer, easier to reuse, repair and recycle. It is necessary to modernize energy-intensive industries and decrease their greenhouse gas emissions, support the industries of sustainable and smart mobility, promote energy efficiency, strengthen existing instruments for the relocation of $\mathrm{CO}_{2}$ and $\mathrm{CO}_{2}$ equivalent emissions and ensure a sufficient and constant supply of low-polluting energy at competitive prices, starting or implementing the activity on clean hydrogen. Finally, the supply of essential raw materials must be guaranteed in Europe and the production of strategic commodities, fine and specialty chemicals in Europe should be relocated.

\section{REFERENCES}

[1] https://ec.europa.eu/environment/circular-economy/

[2] https://ec.europa.eu/commission/presscorner/detail/en/ip $20 \_420$

[3] https://ec.europa.eu/info/law/better-regulation/haveyour-say/initiatives/12095-A-new-CircularEconomyAction-Plan

[4] https: //mk0eeborgicuypctuf7e.kinstacdn. com/wpcontent/uploads/2020/01/EEB-response-toCERoadmap-January-2020.pdf

[5] https://ieep.eu/publications/an-analysis-of-the-new-eucircular-economy-action-plan

[6] https://www.switchtogreen.eu//wordpress/wpcontent/uploads/wp-post-to-pdf-enhancedcache/1/circular-economy-strategy.pdf

[7] https://ec.europa.eu/info/sites/info/files/european-greendeal-communication_en.pdf

[8] https://echa.europa.eu/it/substances-of-very-highconcern-identification

[9] https://www.un.org/ldcportal/stockholm-convention-onpersistent-organic-pollutants-pops/ 